\title{
DO QUALITY CONSULTANTS OFFER A QUALITY SERVICE?
}

\section{INTRODUCTION}

The transition towards an increasingly competitive general economic environment, characterised among other factors by the economic globalisation as well as the technological innovation processes, has resulted in the emergence of a new management style. Even it is rather difficult to generalise and summarise the characteristics of new organisations, and while remaining conscious of the dangers of generalisation, we could mention the following three general characteristics that the new organisations tend to share:

- An intensive reorganisation process of the company, towards more flexible and integrated organisations.

- The customer is settled as the most important and basic figure for the firm.

- The setting-up of the quality paradigm as the model guided to get satisfied the customer, as well as a trend to set new standards for quality.

In Europe, not all firms around us find themselves involved in this type of reorganisation. Obviously, the repercussion of these organisational changes is not uniform - in fact there still exist nowadays many small firms which follow craftsmanship patterns of production. It seems like this tendency is much more evident in large firms and in some specific sectors (e.g., multinationals at the car industry). But it also true that even in small firms there is a greater tendency to reorganise and re-evaluate the productive process, a kind of new paradigm or new common sense in management.

Overall, the quality paradigm has become a considerable force throughout Europe and in the rest of the world. Certainly, this paradigm has transcended from the industrial and economic areas to other wider ones, as well as the social, and sometimes, discussion related to quality has even been popularised in excess. Thus, as is stressed in one of the European Commission's recognised publication, one must be conscious of the fact that

quality is a tool or a means to obtain an end and not an end in itself (Silva and Giannuolo, 1996). Although methods to improve and manage quality are numerous, it can be said that 
this quality paradigm or movement is based on two pillars: ISO 9000 and Total Quality Management.

Lately, the academic field has developed a large number of empirical studies related to ISO 9000 quality systems, at national and international level. Among other considerations, these research studies have attempted to analyse why companies decide to introduce ISO 9000, along with the difficulties involved and the benefits derived from.

This movement in the academic field follows a previous phenomenon in the business field: the high growing rate of the introduction of ISO 9000 standards (ISO, 9000). In a parallel fashion, there has been a notable growth in demand for the specialist services of quality management consultants.

All these studies confirm the importance of the consultant services engaged by companies in order to introduce the new ruling, but the actual influence of these services has not been fully analysed. Nevertheless, obvious questions on the subject spring to mind: What contribution have the consultant services brought to companies that are involved in introducing ISO 9000? Has the consultant service proved beneficial? Are the companies satisfied with the quality consultants? Have the consultants lived up to the expectations of their clients? What benefits are involved?

These questions are obviously of interest to the companies involved but also to consultants eager to determine the degree of client satisfaction, on which their very future depends. Moreover, the analysis of these questions is even more relevant in the present situation where companies are involved in a process of adaptation to the new ISO 9000:2000 standards. For all the above reasons, and in order to resolve the issues thereby raised, the present empirical study was carried out on companies that have used consultancy services to introduce their ISO 9000 quality systems.

\section{ANTECEDENTS}

Most research into quality management at a world-wide level refers to the motivation of companies to introduce quality systems (Wenmoth and Dobbin, 1994; Meegan and Taylor, 1997), to the benefits derived from the introduction of such systems (Lloyd's 
Register Quality Assurance, 1994; Vanguard Consulting, 1994; Brown and Van der Wiele, 1995; Buttle, F. 1997; Jones et al, 1997; Casadesús and Giménez, 2000), or to the importance of the human factor in quality management (Vloeberghs and Bellens, 1996). Many studies mention the importance of the support lent by consultant services for the introduction of the ruling. In this country, previous research showed that approximately $80 \%$ of 286 Spanish companies surveyed use external consultant services (Casadesús, 1998). This can be seen in Graph 1 . The services provided range from in-service training prior to introducing a quality system to maintenance auditing of the system after certification. The service can also include producing the quality manual and drawing up procedures for the quality assurance systems.

<graph 1 here $>$

In like manner, some research studies mention the relative importance of companies that have used external consultancies compared to those that have not (Vloeberghs and Bellens, 1996) but no study has assessed the real quality of the services offered by the consultancies or whether this service was really what the client company expected. Some considerations on the contributions of consultant firms can be found (including factors such as employee training, information and motivation), but no studies have been made on issues of such crucial interest as the following: to what extent does the engagement of a consultant service provide benefits to the firm? Can these benefits be measured? Are the benefits of an intangible nature that is hard to express in monetary terms? This is a complex issue indeed, as has already been pointed out in the literature on the subject (Nachum, 1999), where some authors have put forward their own methodology for calculating the yield from an investment in consultation services (Phillips, 2000).

The present paper aims to summarise the main conclusions drawn from a research study that analyses the expectations and fulfilment of expectations among client companies that have used consultancy services to introduce ISO 9000 quality assurance systems. The 
paper also analyses the benefits obtained by the companies as a result of the introduction of the ruling following advice given by professional consultants.

\section{METHODOLOGY}

An empirical research study has been recently carried out with the aim of analysing and attempting to provide an answer to these questions. A sample was taken of companies that had used consultant services for implementing quality assurance systems in keeping with the ISO 9000 standards on the subject. This model or type of quality management was chosen because it is undoubtedly the most widely used in Spain.

The evolution of the impact of ISO 9000 certification in Spain, it has to be said that the growth in the last years has been spectacular: currently there are more than 8.000 certified Spanish companies, and in these past few years ISO 9000 has been popularised in Spain (Casadesús, Heras and Ochoa, 2000).

At present, more and more people, and not only from the entrepreneurial and academic area, knows or at least has heard about ISO 9000. In this sense, in our opinion, two factors have played an important role: on the one hand, the extension of the certification in itself, that has arrived to a very wide activity sectors, products and services (education, social work, financial services, telebank cards, etc.); and additionally, the intensive promotion carried out by some companies of the ISO 9000 certification as if it were a product or service quality label. One may guess that this popularisation process can affect positively so much as negatively to the future evolution of the norm.

For example, a broad set of advantages has been popularised, some of them objectives and constrastables, and that are derived from the implementation of a quality assurance system, but so many others, on the other hand, not very objectives, derived from a generalised opinion (e.g., the excessive valuation of the quality image improvement of the ISO 9000 certification). The problem of these currents of opinion is that too many times, so soon the management tool in question, in this case ISO 9000, is erected as an authentic panacea, as so soon it is totally reviled and repudiated. 
The research was undertaken in the Catalonian Autonomous Community, which is considered to be one of the regions in Spain where ISO 9000 certification has had the greatest impact. In more specific terms, the research was carried out within the industrial area of Catalonia and focuses on companies that were certified in 1997, 1998 and 1999.

The companies in the sample were sent a questionnaire, composed of some modules: the first one of them to detect perception of the service received; the next to asses previous expectations; the third one to know the benefit of the consultant intervention. Other sections included in the questionnaire get information about the company and the consultant.

The two first modules were adapted from the widespread SERVQUAL model drawn up by Zeithaml et al. (1993). This is a model whereby the quality of a given service is assessed on the basis of the expectations and perceptions of the clients. This is considered to be the best known used system presently used for measuring service quality.

In short, the questionnaire was designed to gather information about the quality of the consultancy service as perceived by companies that engaged the service to introduce ISO 9000 and about the expectations of this type of service that were previously held by the company. With this information, the questionnaire then attempts to find out the benefits that were obtained by the company as a result of engaging the service. Each of these aspects will be considered in the following paragraphs. It must be borne in mind, however, that the responses to these questions have been compiled on a Likert scale [1.5]. The questionnaire was completed by the addition of extra questions designed to obtain general information about the company and about the consultancy that was employed.

The questionnaire was delivered via ordinary mail to 483 managers who are responsible of ISO 9000. After that, these people was contacted by telephone to explain the purpose of the study, and a fax or electronic mail was delivered again to those who agreed to participate. The 87 valid questionnaire represent a response rate of $18 \%$, but only 65 of these came from companies that had used consultancies to introduce their quality system. The population on which the research was carried out is less than 1,670 companies, this 
being the total number of certificates issued over the sample period in Catalonia. It must also be borne in mind that many companies hold more than one certificate.

The questionnaires were grouped in ten different codes of activity to compare with the rate of these codes in the total population. The sample obtained is quite representative of the companies located in Catalonia. Nevertheless, a first conclusion that can be drawn is that there are less proportion of companies in the services sector.

\section{BENEFITS OBTAINED BY CLIENTS OF QUALITY CONSULTANT SERVICES}

Before analysing the quality offered by consultants and the expectations raised by this type of service, an analysis is made of the clients' perception of the benefits directly derived from the consultant's intervention. Although it must be considered a priori that clients are not usually very sure about the value of the service that they are engaging or the price that they are prepared to pay for it, it can be said that if this type of consultancy exists, it is because clients think that they can obtain some benefits for which they are prepared to pay a fee. These benefits have been assessed by a set of thirteen questions, likewise answered on the Likert scale [1.5] as compiled in Table 1. The benefits considered are not merely of an economic nature but include diverse factors such as increased motivation in workers and improved relationships with customers and suppliers.

$<$ Table 1 here $>$

This list has been drawn from some sources, mainly form the eight fundamental concept of the European Foundation for Quality Management model and from the eight principles for the quality management provided by ISO 9000.

Assessment of the results obtained shows that the arithmetic mean of all these benefits is only 3.05. An overall assessment of the benefits gained from use of a consultant was obtained from one single question, the response to which gave the similar result of 3.17. 
In short, both indicators coincide in highlighting the fact that the companies did not perceive any benefits from the input of the consultant.

From a factor analysis, on extracting factors with the principal components and varimax rotation method, two factors with eigenvalues higher than 1 are obtained. The analysis is correct. The determinant of the correlation matrix is $7.162 \mathrm{E}-06$ and the KMO measure is 0.881. The standardized item Cronbach alpha is 0,94 for the first factor and 0,84 for the second. These constructs demonstrate good reliability. Moreover, the two factors account for $70 \%$ of the variability of the sample.

From the variables with the highest saturations in each factor, we decided to call the first factor "Client Approach" (with a punctuation of 2.9) and the second factor "Before the ruling is introduced" $(3,4)$. This second factor includes all the benefits derived from the steps prior to introduction: definition of quality policy, identification of aims, definition of procedures and improved understanding of quality (see graph 2).

$<$ Graph 2 here $>$

The first dimension (client approach) is slightly under the middle of the Likert scale used. The work of the consultant doesn't help companies to improve its approach to clients. The second dimension gets a better punctuation, what means the consultant makes a good work before implementation the quality system.

Table 2 shows the grouping of the items related to benefits derived from working with a quality consultant.

$<$ Table 2 here $>$

\section{PERCEIVED QUALITY OF THE QUALITY CONSULTANT SERVICES}


In their well known model, the authors Zeithaml et al. (1993) distinguish five different dimensions that define the quality of a given service:

- Tangibles: appearance of the physical facilities, equipment, personnel and communication equipment.

- Reliability: ability to perform the promised service dependably and accurately.

- Responsiveness: willingness to help clients and provide prompt service.

- Assurance: knowledge and courtesy of employees and their ability to inspire trust and confidence

- Empathy: caring, individualised attention the firm offers its clients.

The quality of the service as perceived by clients will be derived from comparing their prior expectations of the service with their appreciation of the actual service provided, in such a way that a given service will be considered excellent for the client when the benefit exceeds prior expectations, acceptable when the benefit lives up to the client's expectations and deficient when the service is poorer than expected.

In order to determine the perceived quality, a questionnaire extracted mainly form the SERVQUAL model was used, with a total of 14 questions in all. It should be noted, however, that we adapted these questions to our circumstances, following guidelines laid down by different questionnaires used in other empirical studies. To this end, the following studies should be mentioned: research by Samson and Parker (1994) into the engineering consultancy industry in Australia; research by Domingo Ribeiro (1996) into the consultancy sector in Valencia; the study by Casadesús (1998) of the introduction of ISO 9000 into Catalonia; and a paper by Escanciano (2000) on quality systems in Spain.

Table 3 shows the grouping of the different questions or items in each of the dimensions of Ziethaml model. The aggregation was made "a priori", but there was no mention of dimensions in the questionnaire.

$<$ Table 3 here $>$ 
The reliability of the data was examined for the 14 perception-item using the Alpha of Cronbach: the standard value is 0.9355 , and the 14 Alphas obtained when one of the items is deleted are all between 0,9271 and 0,9356 .

The data collected during field work referring to the quality of the consultancy services as perceived by the companies was analysed following the principal components method. In this way, after the varimax rotation method was applied, only three factors with eigenvalues greater than 1 were obtained. The contrast analysis is correct: the determinant of the correlation matrix is $1.055 \mathrm{E}-5$, and the Kaiser-Meyer-Olkin measure is 0.834 . These three factors combine to explain the $72.3 \%$ of the total of the variance (see annex 1).

On the other hand, it can be deduced from the grouping of questions about perceived quality suggested by the factor analysis that a relative similitude exists to the generic model by Zeithaml et al. (1993). Table 4 shows the dimensions of the Ziethaml et al. model in the column headings. The factors determined by the factor analysis figure in the rows underneath. Analysis of this table shows the relationship between both forms of grouping the fourteen questions on perceived quality that figure on the questionnaire.

$<$ Table 4 here $>$

The three factors that define the perceived quality of ISO 9000 consultancy service are the following:

- Factor 1: Personal quality of the consultant. This factor refers to a set of aspects such as the consultant's knowledge of the ruling, involvement of the consultant in the client company's interests, care and individualised attention given by the consultant to the company, the consultant's willingness to help, and the climate of trust and confidence that is transmitted to the client. This first quality perception factor is given an average rating of 3.89 on a scale of 1 to 5 . 
Actually, this factor include fully the items of the last three dimensions of the Zeithaml et al. model, and also includes an item that a priori was in reliability dimension. A deeper observation of these items makes evident that all of them are related with the personal work of the consultant.

- Factor 2: Scheduling. The scheduling factor represents the skills of the consultants in completing the work within the agreed time periods. It refers thus to the result of the service, i.e. the obtaining of the certificate within the established budget and time period. This factor should be a sine qua non condition for good service because it is assumed that the providers of a service must fulfil their promises. On the whole, clients do not give any extra credit to companies that honour their obligations, but when this is not the case, poorer quality in the service is detected here with a 3.50 on the same scale. This is an indication that this aspect of the service should be significantly improved.

- Factor 3: Tangibles. This last factor refers to the office appearance, to the equipment used therein and even to the personal appearance of the consultants. The perception detected in this factor is rated at 3.62 .

A first conclusion to be drawn from the results is that the quality of the service is good. The three factors that define the perception are above 3.5 (see graph 3 ).

$<$ Graph 3 here $>$

Several additional factors also exist to bear up this statement.

- The arithmetic mean of the Likert scale ratings [1.5] corresponding to the set of fourteen questions on perceived quality is 3.75 . This is considerably higher than 3 , the central value of the scale. This can be taken as an indicator of a good perception of quality, while still, however, allowing for improvement. This assessment fully 
coincides with a question on "overall perception of the quality of the service" that received an average rating of 3.69, thereby validating the results obtained.

- The statement "working with the consultant was a worthwhile experience" is rated with an average of 3.80. This is not a direct question on quality, but gives us an idea of the degree of satisfaction with the service received.

- The statement "If I were to reinitiate the process, I would choose the same consultant" was rated at 3.55. Actually this question could be asked in terms of yes or not, but the Likert scale gives a degree. It must be borne in mind here that $55 \%$ of the companies have in fact returned to the same consultant after receiving their certificate (not necessarily for quality-related tasks). This is a high index considering that the specific purpose of the introduction process is fulfilled on obtaining certification. If the companies continue to use the consultant after this point, it would seem to indicate a high degree of satisfaction.

- Another index of satisfaction with the service received is the intention to use the same consultant to adapt the company system to the new (ISO 9000:2.000) standards. Seventy-seven per cent of the companies that intend to use a consultancy to update their systems will re-use the same service.

\section{EXPECTATIONS OF SERVICE GIVEN BY QUALITY CONSULTANTS}

Company expectations of the services given by consultants was researched using the same methodology and analysing the same aspects and equivalent sets of questions to those already used to assess perceived quality in the same services.

In the questionnaire there was also included a section in witch a hundred points should be assigned to the five dimensions of the Zeithaml et al. model (1993), balancing the importance of them.

From the results obtained, it can be observed that the most important of the five dimensions defined by the Zeithaml et al. model, is considered to be "Reliability" (in which the consultant delivers the agreed service in an accurate and trustworthy manner). 
From a total of 100 points for all five dimensions, "Reliability" received 28 points whereas "Tangibles" were considered of lesser importance and were only awarded 12 points. However, this same "Reliability" dimension, most closely related to the "Scheduling" factor, coincides exactly with the lowest rated factor in terms of service quality. This points to an urgent need for the consultants to improve this factor.

The relative importance of these dimensions are very similar to the results obtained by Zeithaml et al. (see graph 4).

\section{$<$ Graph 4 here $>$}

On quantifying the level of quality expected from these services, using another set of fourteen questions equivalent to the previous set (on the same scale), the arithmetic mean is found to be 4.35. Thus, expectations of the service are much higher than perceived quality of the same. In short, it is clear that the difference generated between the arithmetic mean of perceived quality of the service and expectations of the same is $-0.61(-12 \%)$. Thus, although a high perception of quality for services rendered by quality consultants was detected in the previous section, prior expectations of the same services were even higher.

If we analyse the gap between expected quality and the quality that is actually perceived, on the basis of the factors that define service quality, as seen above, it can be observed from Graph 5 that the gap is greatest in the "Scheduling" factor, and least significant in the "Tangibles" factor.

$<$ Graph 5 here $>$

In a nutshell, we can conclude this part of the analysis by stating that although the companies hold a good opinion of the quality of the advisory services received, prior 
expectations of the same were considerably higher. This conclusion shows that there is still room for improvement of the service offered by quality consultants.

\section{RELATIONSHIP BETWEEN PERCEIVED QUALITY AND BENEFITS PROVIDED BY THE CONSULTANT}

The next step consisted in establishing the relationship between perceived quality and the benefits obtained from using the service of a consultant. The research study detected and confirmed the relationship existing between the two concepts with different sets of statistics. To summarise, this relationship was analysed in two different ways: firstly, from questions eliciting an overall assessment on quality and benefits, i.e. the analysis of the contingency table resulting from the crossing of the two variables; and secondly, from the analysis of the relationship between the variables of mean quality and mean benefits calculated as a mean from the corresponding sets of questions.

Contingency table 5 relating the two overall assessment variables on the Likert scale [1.5] is a 5x5 square table. The two questions crossed are "make a global evaluation of the consultant" and "make a global evaluation of the benefits provided by the consultant". In this respect, the Pearson chi-square statistics and the likelihood ratio indicate the existence of a relationship.

The association measurements that are normally used on an ordinal scale (Gamma $=$ 0.759 , Kendall's tau- $b=0.563$ and Somers' $d=0.562$, each with a $\mathrm{P}$ value of 0.000 in every case) also detect a relationship between the different variables. A log-linear model was set up to explain the frequencies in the contingency table cells and the saturated model was found to be the most suitable for the purpose. This model includes the interaction between the two variables.

Insert Table 5

To sum up, it has been statistically shown that the variables have a clear positive correlation. The higher the perceived quality, the higher the benefits, and vice-versa. 
On the other hand, and as a second way of detecting and defining a relationship, a linear regression was made between two variables that were calculated as the mean from the set of questions on perception and the mean from the questions on benefits (see graph 6). The analysis indicates that the variables are correlated, although the Pearson correlation coefficient is 0.588 , with zero significance level.

$<$ Graph 6 here $>$

Proceeding logically, the very design of the variables enables the rank in both cases to be [1.5]. Both cases present variables of a linear combination of several questions answered on the Likert scale [1.5]. The relationship between the variables can be clearly seen on the graph. Leaving the mean perceived benefit as an independent variable, the linear regression has been calculated as:

\section{Mean Arithmetic Benefit $=0.456+0.702 *$ Mean Perceived Quality}

The slope of the regression is positive, but less than the unit. A unitary increase in quality does not result in a unitary increase in benefits, but only in an increase of seventeenth. The regression coefficient associated with the dependent variable obtained a zero significance level.

In summary, the analyses point to the existence of a significant relationship between the efforts of the consultant to provide a better quality service and the client's perception of improved benefits.

\section{QUALITY OF CONSULTANT COMPANIES IN RELATION TO THEIR SIZE}

A study of the performance of consultant companies in relation to their size was made on the basis of the collected data. The sample was divided into four categories: companies that engaged the services of a single independent consultant (23\% of the sample) ; companies that used consultancies with a staff of between 2 and 5 consultants $(36 \%)$; companies that used consultancies with a staff of between 6 and 50 consultants $(32 \%)$; 
and lastly companies that used consultancies with a staff of over 50 consultants $(9 \%)$. The results of this segmentation can be seen in Graph 7.

$<$ Graph 7 here $>$

It was observed that the perceived quality of the service is related to the size of the consultant company: the larger the company, the better the perception. The big consultant companies obtain a significantly higher perception rating than the smaller companies. Whereas small companies (with 2 to 5 consultants) obtain an average rating of 3.39 , the average rating of the consultancies with a staff of over 50 employees stands at 4.43 . This represents a large difference of over one point. It is noteworthy, however, that professional consultants working independently offer a high quality service and score a rating that is closer to that of the large consultancies than the small ones.

There also seems to be a negative relationship between the expectations of the client company and the number of workers employed by the consultant company. However, this does not carry any statistical significance.

In the case of consultants working alone as independent professionals, expectations of the service and perceived quality of the same are both very high. On the other hand, although their clients have lower expectations, the large consultant companies offer the best quality service. In this case, indeed, perceived quality is higher than expectations.

Kruskal-Wallis test carried out by grouping the variables according to the size of the consultant companies (table 6). Although there is no statistical evidence that the benefits provided differ from one group to another, nevertheless small companies (between 2 and 5 consultants) provide the fewest benefits for their clients (rate of 2.88), whereas the large companies obtain an average rating of 3.13 .

$<$ Table 6 here $>$ 
Once again, it is noted that independent professional consultants follow a different pattern and obtain the highest ratings of all (3.24). It can be noted as well in the graph of each benefit factor (graph 8).

$<$ Graph 8 here $>$

The perceived quality and the gap between expectations and perception both present significantly different averages with a significance level of 0.05 .

In a parallel manner, the performance of the variables of quality, expectations and benefits was analysed in relation to the size of the client company. In short, no statistically significant relationship was detected between these variables and the size of the client company in terms of number of employees.

\section{COST OF CONSULTANT SERVICES}

It is difficult to assess the benefits obtained from a consultant service without taking into consideration the cost of the same. For this reason it was considered appropriate to analyse the questionnaire in terms of the costs involved. In brief, it can be concluded from an analysis of the data that these services are not expensive. An assessment of the fees charged gives the lowest rating of the whole questionnaire, i.e. 2.72. This value is lower than the average value of the scale, thus indicating a slight variance with the above statement.

Companies invest few resources in the introduction of the ruling. It was found that $62 \%$ of the sample invested less than 15.000 euros. Among the companies that engaged the services of a consultant, the corresponding fees amounted to $48 \%$ of the total cost of introduction. In most cases $(77 \%)$, the consultant's fees are stipulated right from the beginning. It can be assumed that the consultancies are so familiar with their service that they can make an initial estimate of the cost of introducing the ruling with a high degree 
of precision. This type of service has been steadily growing ever since it was started a decade ago and can therefore be considered as standard (Martinez et al., 2000). Moreover, it is interesting to note that the offer of the service has also increased, which has resulted in a corresponding price adjustment.

\section{CONCLUSIONS}

One of the characteristics that differentiates a service from a product or material goods is that the service is sold first and later "manufactured". Moreover, the production and consumption of the service are simultaneous, i.e. a service cannot be stored. Thus, the overall assessment of the client springs from two sources: the end result of the service and the very process by which the service is provided (Berry, 1995).

For these reasons, the assessment of the quality of a service is not an easy task and, as pointed out by Gorth and Dye (1999), the providers of a service should bear in mind this dual aspect by which a service is appraised. They should therefore be able to recognise the different degrees by which the service itself and the provision of the service are being assessed. Despite this, we consider it important to assess these services from the point of view of the client company, as has been done in the present research study.

From all this, we can draw the overall conclusion that the ISO 9000 advisory services are favourably regarded on the whole. However, it should also be noted that clients expect an even higher quality. In short, the client companies expect a higher quality from the service than that which is actually provided.

It has been shown that the concept of quality can be broken down into three factors, one of which is the skill of the consultant in introducing the ruling within the agreed time period, and this is the aspect of the service that obtains the poorest quality rating. This factor is closely linked to the reliability factor, which is considered to be of the highest importance by the client companies. For this reason, the most reiterated request for improvement by the clients is that the consultants perform the required tasks within the agreed time periods. 
Moreover, the results of the study show that the performance of independent professional consultants is very different to that of small consultant companies. Independent consultants offer a high quality service that lives up to the very high expectations of their clients. The benefits that these clients gain from working with a consultant are also perceived as very high.

Finally, it has been noted that the quality offered by consultant companies that employ a staff of professionals varies according to the size of the company. The benefits perceived by their clients are very similar but are slightly higher to those perceived by companies employing large consultancies.

\section{BIBLIOGRAPHY}

Berry, Leonard L. (1.995): "Más allá de la excelencia en el servicio. Un plan para la acción”. Deusto Publications.

Brown, A. and Van der Wiele, T. (1995): "Industry experience with ISO 9000", Asia Pacific Journal of Quality Management, Vol. 4, No. 2, pp. 8-17.

Buttle, F. (1997): "ISO 9000: marketing motivations and benefits", International Journal of Quality \& Reliability Management, Vol. 14, No. 9, pp 936-947.

Casadesús, M.. (1998): "La normativa de aseguramiento de la calidad ISO 9000 en Cataluña: expectativas y efectos. Estudio empírico”. Research project CICYT. Reference: SEC96-1005.

Casadesús, M. and Giménez, G. (2.000): "The benefits of the implementation of the ISO 9000 standard: empirical research in 288 Spanish companies”. The TQM Magazine, Vol 12 Issue 6 Date 2000.

Casadesús, M.; I. Heras, and C. Ochoa, C. 2000. The benefits of the implementation of the ISO 9000 normative. Empirical research in the Spanish companies. First World Conference on Production and Operations Management. POM Sevilla.

Escanciano García-Miranda, Carmen (2000): "Influencia de la certificación ISO 9000 en el avance de la empresa española hacia la calidad total". First World Conference on Production and Operations Management POM Sevilla 2000. 
Groth, John C. and Dye, Richard T. (1999): "Service quality: percived value, expectations, shortfalls, and bonuses”, Managing Service Quality, Vol 9, Issue 4 Date 1.999.

ISO (2000) . http://www.iso.ch/iso/en/iso9000-14000/pdf/survey9.pdf

Jones, R., Arndt, G., and Kustin, R. (1997): "ISO 9000 among Australian companies: impact of time and reasons for seeking certification on perceptions of benefits received", International Journal of Quality \& Reliability Management, Vol. 14, № 7.

Lloyds Register Quality Assurance Ltd (1994): BS 5750/ ISO 9000 - Setting Standards for Better Business, Lloyds Register Quality Assurance Services Ltd, Croyden.

Martínez, Clara et al (2000): “Analysis of the implementation of ISO 9000 quality assurance systems". Work study, Vol 49 Issue 6.

Meegan, S.T. and Taylor W.A. (1997): "Factors influencing a successful transition from ISO 9000 to TQM. The influence of understanding and motivation”, International Journal of Quality \& Reliability Management, Vol. 14, No. 2.

Nachum, Liliach (1999): "Measurement of productivity of professional services. An illustration on Swedish management consulting firms." International Journal of Operations \& Production Management, Vol 19, Issue 9.

Phillips Jack (2000): “The consultant's scorecard”, McGraw Hill.

Ribeiro, Domingo (1996). "Consultoría para la dirección en organización, calidad, marketing y estrategia”. Doctoral thesis University of Valencia (Spain).

Samson, Danny and Parker, Rod (1994): "Service Quality: the gap in the Australian Consulting Engineering Industry”, International Journal of Quality \& Reliability Management, Vol 11 Issue 7.

Silva, A. and Giannuolo, G. (1996). "The Social impact of Quality Policy Implementation on European Industry”, Compilation of Quality Series Documents. The European Quality Promotion Policy, European Commision, DG III - Industry, Brussel.

Vanguard Consulting Ltd (1994): “BS 5750/ISO 9000/ EN 29000: 1987, a positive contribution to better business", The TQM Magazine, Vol. 11 No. 2, p. 60.

Vloeberghs, D. and Bellens, J. (1996): "Implementing the ISO 9000 standards", Quality Progress, Vol. 29 No. 6, pp. 43-48. 
Zeithaml, Valarie A.; Parasuraman, A. and Berry, Leonard L. (1993): "Calidad total en la gestión de los servicios". Díaz de Santos. 


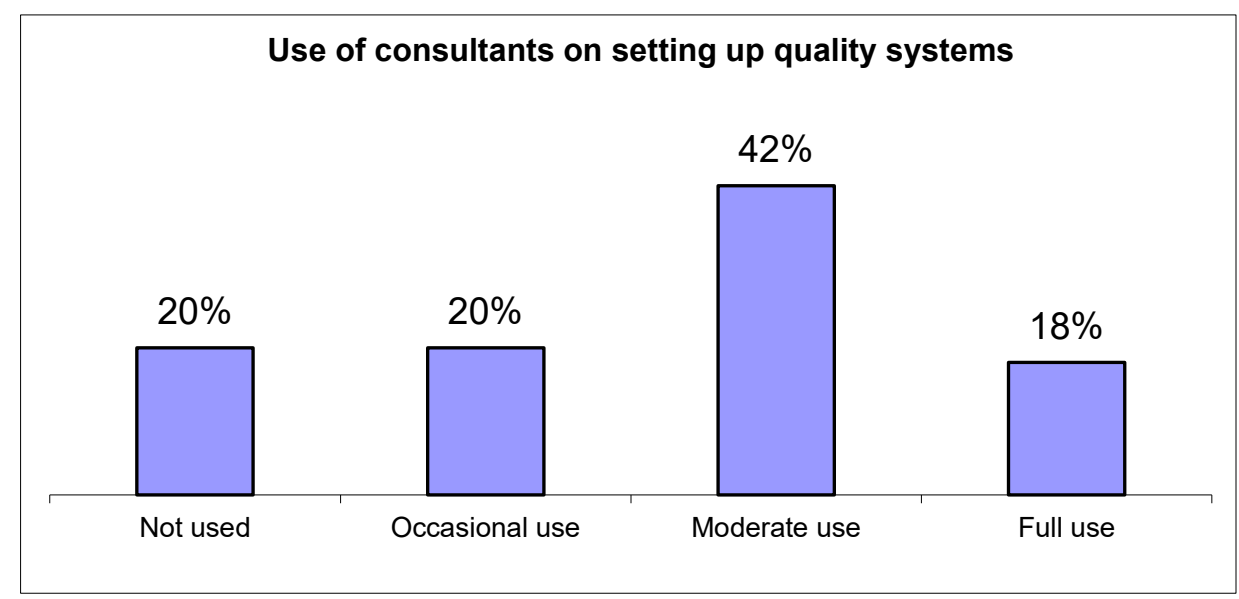

Graph 1. Percentage of companies that have used consultant services when introducing quality systems (Casadesús, 1998)

\begin{tabular}{|l|l|}
\hline & ITEMS \\
\hline 1 & Better understanding of quality as a result of working with an external consultant \\
\hline 2 & Satisfaction with the skills provided by the consultants \\
\hline 3 & Increased company motivation after working with external consultants \\
\hline 4 & Adaptation of ethical approach after working with an external consultant \\
\hline 5 & Definition and aims of quality policy following advice from the consultant \\
\hline 6 & Definition of and approach to processes following advice from the consultant \\
\hline 7 & Improved approach to customers following advice from the consultant \\
\hline 8 & Setting up of beneficial relationships with customers and/or suppliers following advice from the consultant. \\
\hline 9 & Setting up of customer satisfaction control measures following advice from the consultant. \\
\hline 10 & Ideas for growth of company yield following advice from the consultant. \\
\hline 11 & Setting up of continuous improvement scheme in the company following advice from the consultant. \\
\hline 12 & $\begin{array}{l}\text { Improved understanding of the relationship between the different processes and how to manage the same in terms } \\
\text { of a system }\end{array}$ \\
\hline 13 & Improved decision-taking based on data analysis following advice from the consultant. \\
\hline
\end{tabular}

Table 1. Items analysed to assess the benefits of working with a consultant when introducing a quality system. 


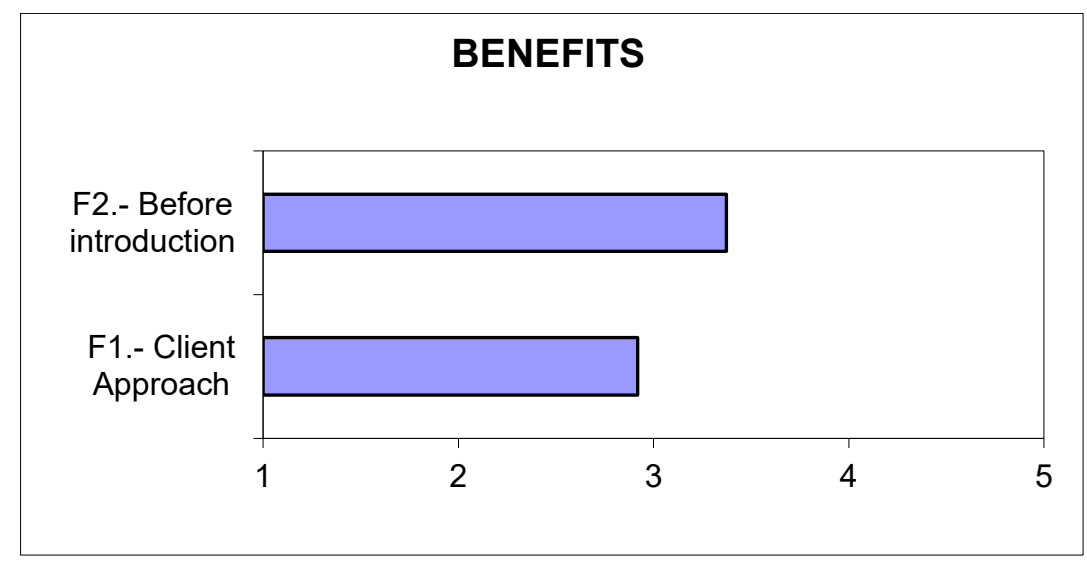

Graph 2. Punctuations of Benefit factors.

\begin{tabular}{|l|c|c|c|c|c|c|c|c|c|c|c|c|c|}
\cline { 2 - 12 } \multicolumn{1}{c|}{} & 1 & 2 & 3 & 4 & 5 & 6 & 7 & 8 & 9 & 10 & 11 & 12 & 13 \\
\hline Factor 1 & & $\mathrm{X}$ & $\mathrm{X}$ & & & & $\mathrm{X}$ & $\mathrm{X}$ & $\mathrm{X}$ & $\mathrm{X}$ & $\mathrm{X}$ & $\mathrm{X}$ & $\mathrm{X}$ \\
\hline Factor 2 & $\mathrm{X}$ & & & $\mathrm{X}$ & $\mathrm{X}$ & $\mathrm{X}$ & & & & & & & \\
\hline
\end{tabular}

Table 2. High saturation of the two factors of benefits with the PAF method with varimax rotation.

\begin{tabular}{|l|l|l|}
\hline \multicolumn{2}{|l|}{ Factor } & Description of items \\
\hline 1: Tangibles & 1 & Personal appearance of staff. \\
\cline { 2 - 3 } & 2 & Visual attractiveness of equipment in the consultancy. \\
\cline { 2 - 3 } & 3 & Easy reports to understand. \\
\hline \multirow{3}{*}{ 2: Reliability } & 4 & Ability to perform the promised service \\
\cline { 2 - 3 } & 5 & Fulfilment of commitments within the established time limits \\
\cline { 2 - 3 } & 6 & Co-ordination between different company departments \\
\cline { 2 - 3 } & 7 & Detailed specification of aims and time limits \\
\hline \multirow{3}{*}{ 3: Responsiveness } & 8 & Willingness to help clients \\
\cline { 2 - 3 } & 9 & Enthusiasm and involvement in the project. \\
\hline 5: Empurance & 10 & Ability to inspire trust and confidence \\
\cline { 2 - 3 } & 11 & Professional knowledge and expertise of consultants \\
\cline { 2 - 3 } & 12 & Company concern for the best interests of the client \\
\cline { 2 - 3 } & 13 & Communication and interpersonal skills of the consultant \\
\cline { 2 - 3 } & 14 & Client satisfaction with consultation \\
\hline
\end{tabular}

Table 3. Distribution of the 14 items surveyed in relation to the different dimensions of the model proposed by Zeithaml et al. (1993) 


\begin{tabular}{|l|c|c|c|c|c|c|c|c|c|c|c|c|c|c|c|}
\cline { 2 - 14 } \multicolumn{1}{c|}{} & \multicolumn{4}{c|}{ Tangibles } & \multicolumn{4}{c|}{ Reliability } & \multicolumn{3}{c|}{ Responsiveness } & \multicolumn{3}{c|}{ Assurance } & \multicolumn{3}{c|}{ Empathy } \\
\cline { 2 - 14 } \multicolumn{1}{c|}{} & 1 & 2 & 3 & 4 & 5 & 6 & 7 & 8 & 9 & 10 & 11 & 12 & 13 & 14 \\
\hline Factor 1 & & & & $\mathrm{X}$ & & & & $\mathrm{X}$ & $\mathrm{X}$ & $\mathrm{X}$ & $\mathrm{X}$ & $\mathrm{X}$ & $\mathrm{X}$ & $\mathrm{X}$ \\
\hline Factor 2 & & & & & $\mathrm{X}$ & $\mathrm{X}$ & $\mathrm{X}$ & & & & & & & \\
\hline Factor 3 & $\mathrm{X}$ & $\mathrm{X}$ & $\mathrm{X}$ & & & & & & & & & & & \\
\hline
\end{tabular}

Table 4. High saturations of the three factors with the principal component method with varimax.

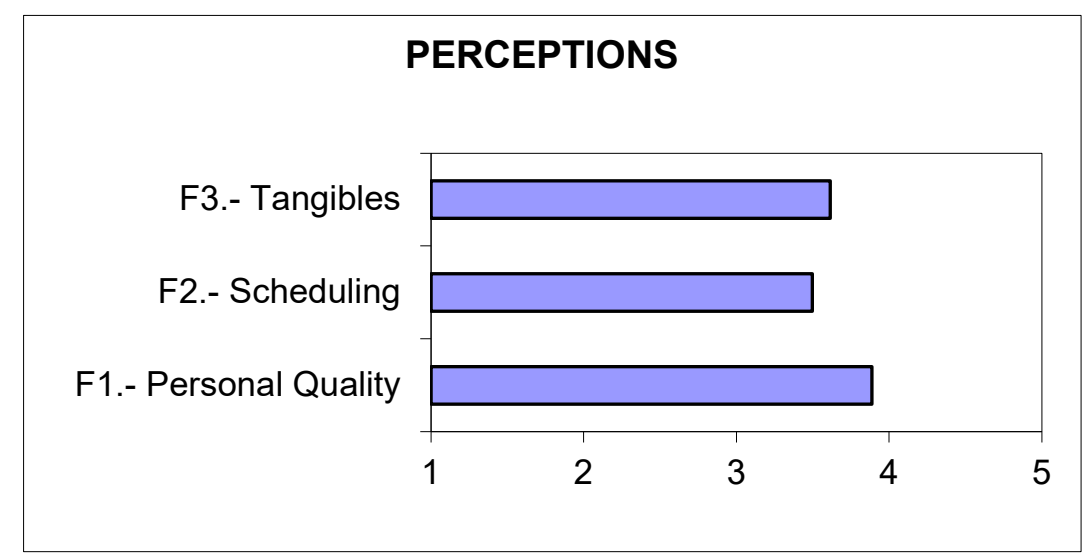

Graph 3. Punctuations of perceived quality factors. 


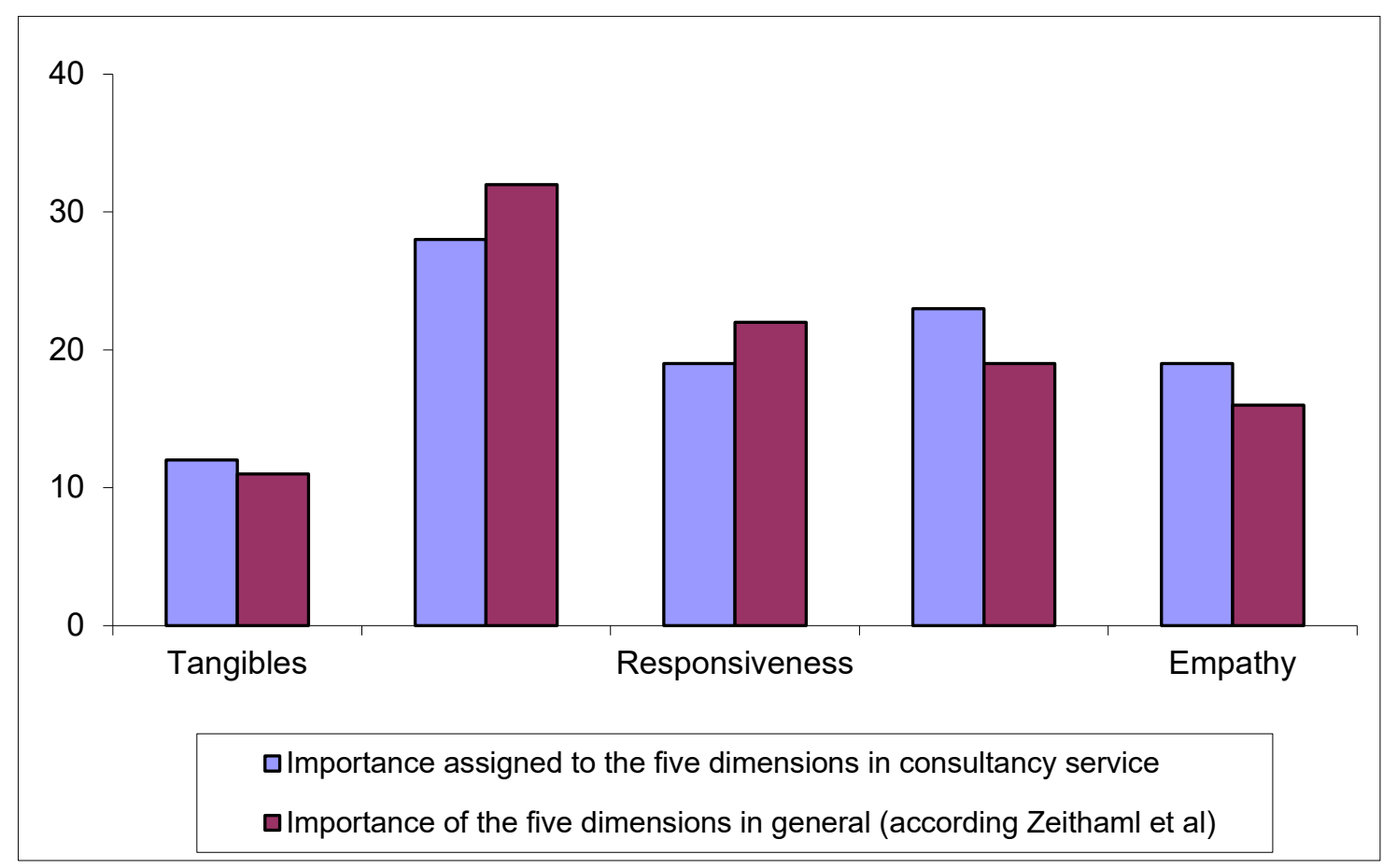

Graph 4. Relative importance assigned in the consultancy service versus the figures detected by Zeithaml et al.

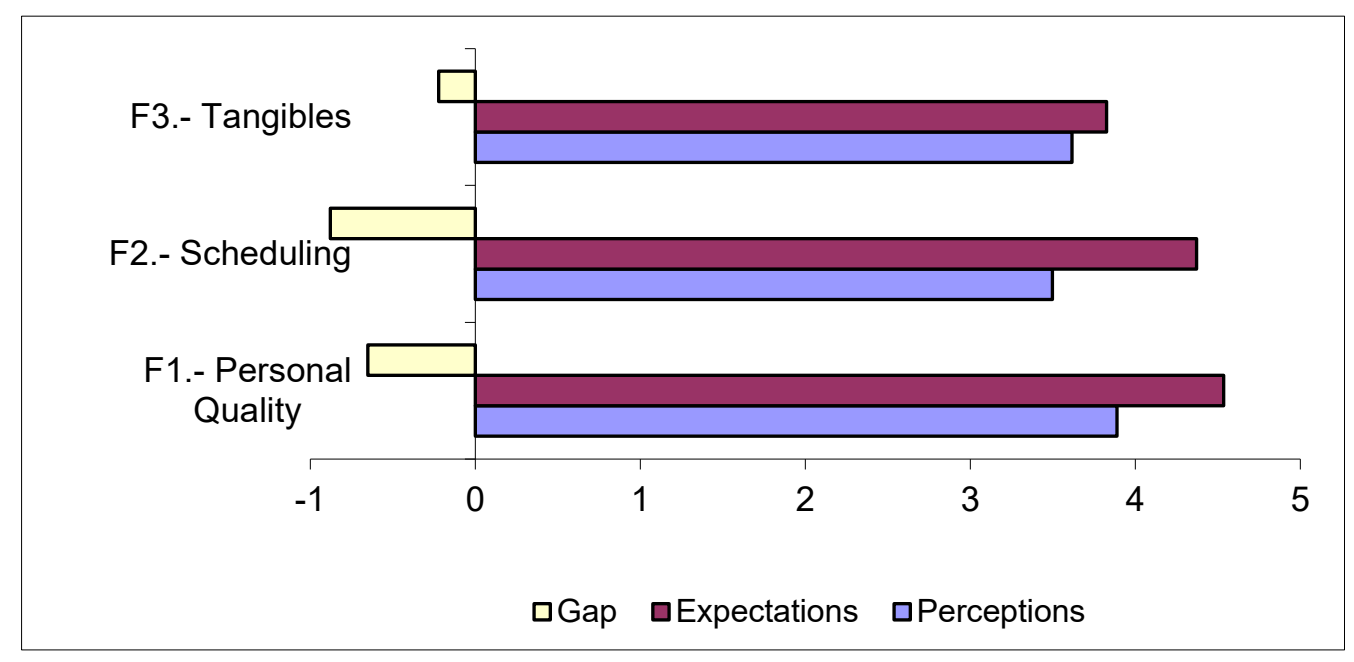

Graph 5. Perceived quality, expected quality and the gap between expectations and quality in each of the three factors used to define service quality.

\section{Chi-square tests}




\begin{tabular}{|l|l|l|l|}
\hline & Value & $\begin{array}{l}\text { Freedom } \\
\text { Degree }\end{array}$ & (Bilateral) asymptotic sig. \\
\hline Pearson's chi-square & $52.979^{\mathrm{a}}$ & 16 & .000 \\
Likelihood ratio & 45.709 & 16 & .000 \\
Linear by linear association & 27.12 & 1 & .000 \\
Number of valid cases & 62 & & \\
\hline
\end{tabular}

a. 22 cells $(88.0 \%)$ have an expected frequency of less than 5 . The minimum expected frequency is .24 .

Table 5. Contingency table statistic between overall perceived quality and overall benefits.

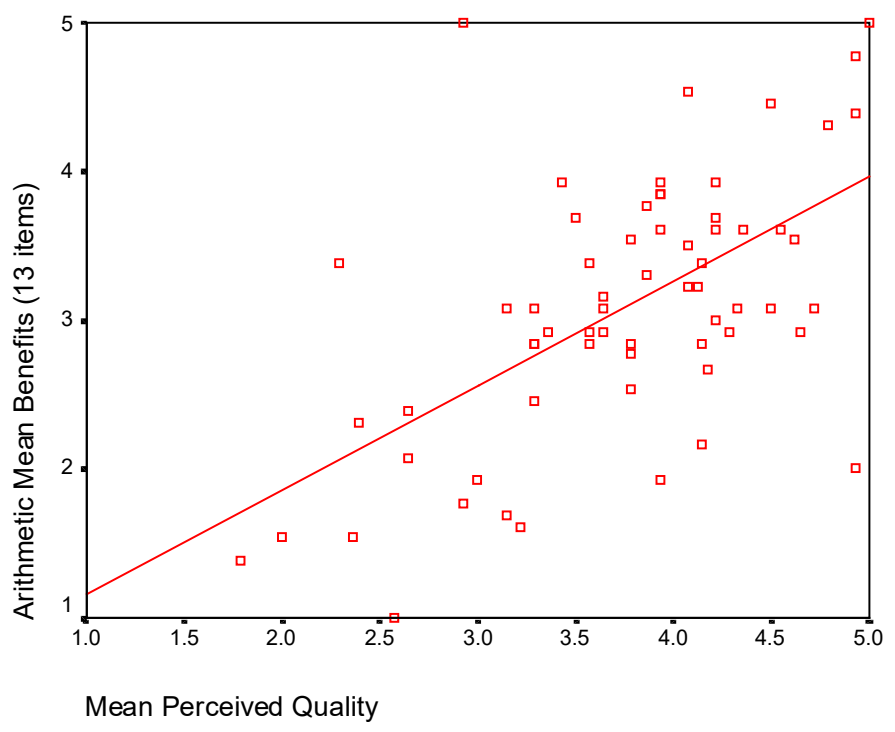

Graph 6. Scatter diagram of the variables "Mean perceived quality" and "Mean benefits". There has been adjusted a lineal regression. 


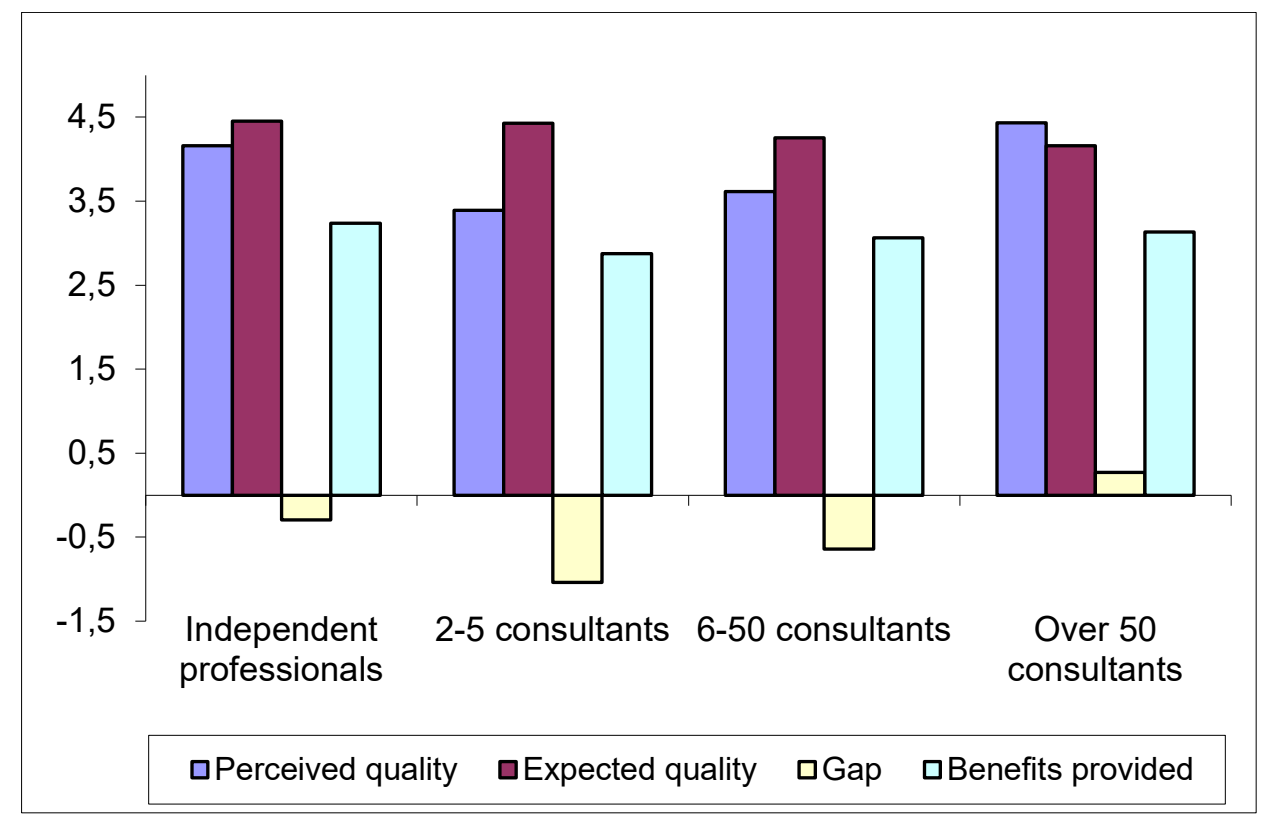

Graph 7. Perceived quality, expectations, gap and benefits in relation to the size of the consultancy.

\section{Contrast statistics $^{a, b}$}

\begin{tabular}{|c|c|c|c|c|}
\hline & $\begin{array}{l}\text { Mean perceived } \\
\text { quality }\end{array}$ & $\begin{array}{l}\text { Mean } \\
\text { expectations }\end{array}$ & $\begin{array}{l}\text { Non-weighted } \\
\text { quality gap }\end{array}$ & $\begin{array}{l}\text { Arithmetic mean } \\
\text { benefits } 13 \text { items }\end{array}$ \\
\hline Chi-square & 14.65 & 1.913 & 14.11 & 1.890 \\
\hline Freedom Degree & 3 & 3 & 3 & 3 \\
\hline Asymptotic sig. & .002 & .591 & .003 & .596 \\
\hline
\end{tabular}

Kruskal-Wallis test

Grouping variable: Number of consultants

Table 6. Kruskal-Wallis test statistics for the variables "Perceived quality", "Expectations", "Gap between expectations and perceived quality" and "Mean benefits" when grouped by "Number of consultants". 


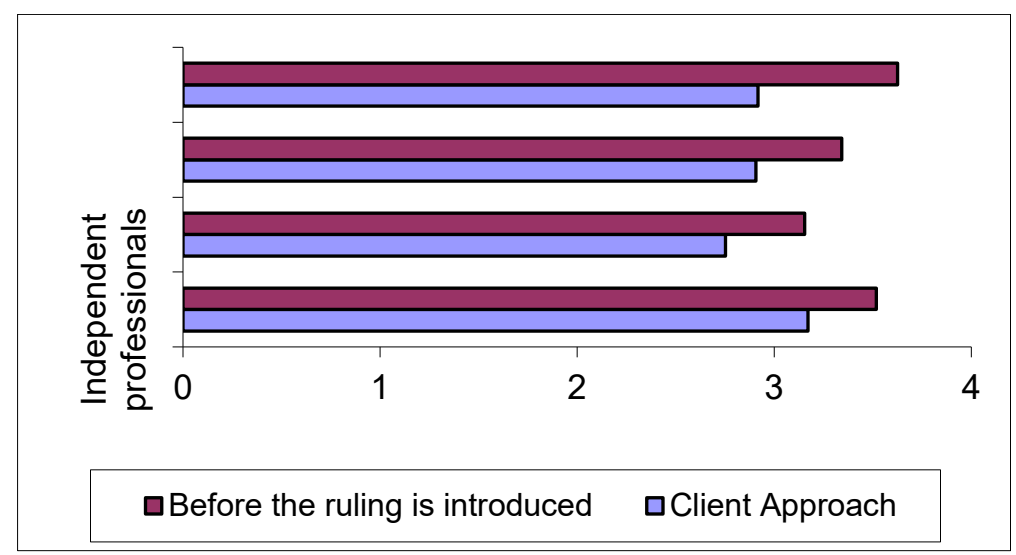

Graph 8. Benefits in relation to the size of the consultancy. 